AWEJ for Translation \& Literary Studies, Volume 6, Number1. February 2022

Pp.53-66 DOI: http://dx.doi.org/10.24093/awejtls/vol6no1.5

\title{
Narrative Aspects of the Novels by Lucy Maud Montgomery and Eleanor Porter
}

\section{Lidiia Matsevko-Bekerska}

Department of World Literature, Faculty of Foreign Languages, Ivan Franko National University of Lviv, Ukraine

Corresponding Author: Imacevko@ukr.net

\section{Olha Nikolenko}

Department of World Literature, Faculty of Philology and Journalism, Poltava V.G. Korolenko National Pedagogical University, Ukraine

Roksoliana Kokhan

Department of Foreign Languages for Natural Sciences, Faculty of Foreign Languages, Ivan Franko National University of Lviv, Ukraine

\section{Kateryna Nikolenko}

Department of World Literature, Faculty of Foreign Languages, Ivan Franko National University of Lviv, Ukraine

Received: 11/28/2021

Accepted: 2/3//2022

Published: 2/24/2022

\begin{abstract}
The metamodernist mood of the modern era increasingly clearly correlates with the transformation of literary methodologies and methods of reading, analysis, and interpretation of literary texts. The study of the genre specificity of the novel is one of the essential segments of the latest scientific studies, given its flexibility and significant textual representation in various national works of literature. This paper offers a critical review of the key stages in the history of the study of the novel as a literary genre, as well as shows the possibilities of understanding the poetic aspects of the author's style. The material of the research relies on the novels by the Canadian writer Lucy Maud Montgomery and the US writer Eleanor Porter. Both authors belonged to the same historical and cultural era; their work has many typological parallels due to objective factors. At the same time, the modernist worldview was embodied in each stylistic manner in its own way. Comparison of individual styles makes it possible to carry out a typological analysis within a particular genre with access to the study of common sources of image creation, as well as modeling the interpretive paradigm of metamodernism in the projection on the literature of different historical periods taking into account national characteristics. At the same time, the research opens up the prospect of expanding the methodological horizons of narratology for its progress beyond its "boundaries": outside of literary studies, in a significant context, as well as in space outside of fiction.

Keywords: Eleanor Porter, genre, interpretation, Lucy Maud Montgomery, metamodernism, modernism, narratology, novel, reception

Cite as: Matsevko-Bekerska, L., Nikolenko,O., Kokhan, R. \& Nikolenko, K. (2022). Narrative Aspects of the Novels by Lucy Maud Montgomery and Eleanor Porter. Arab World English Journal for Translation \& Literary Studies 6(1) 53-66. DOI: http://dx.doi.org/10.24093/awejtls/vol6no1.5
\end{abstract}




\section{Introduction:}

Contemporary literary discourse is increasingly approaching metamodernist feelings and experiences. The proven methodologies and techniques of reading, analysis, interpretation of the literary text acquire a new quality because the significant achievements of previous decades form a scientific and terminological context and determine the vectors for future progress in research horizons. One of the current areas of modern literature is the study of genre specifics of the novel - from a critical review of key stages in the history of its research to the poetic study of aspects of the author's style (in particular, based on the literary works by Lucy Maud Montgomery and Eleanor Porter).

\section{Literature review.}

Despite the fact that novel is one of the most meticulously explored literary genres, it presents new avenues for research, highlighting new methodological possibilities and examining poetic representations of a particular author's style. G.W.F. Hegel's Lectures on Aesthetics provided a thorough foundational basis for further scholarly exploration of the novel as a genre, accentuating some of its inherent aspects: breadth and width of life depicted in the novel; conflict between "poetry of the heart and the prose of real-life situations"; the significance of personality; character development mode(s); connection with the epic, their similarities, and differences (Hegel, 1971, p. 149). Since then, various interpretations of the novel have been proposed by multiple scholars favoring different factors as classification criteria: volume, belonging to the epic mode, the portrayal of individual and social life, etc.

Esalnek (1991) proposed examining the novel from the viewpoint of its system and structure. She developed a structural approach, the foundation of which had been laid by $\mathrm{Yu}$. Lotman. Esalnek (1991) interprets the notion of the system as a combination of elements and structure as their interconnectedness, arrangement, and organization (Esalnek, 1991). Hungarian researcher G. Lukács and Russian scholar M. Bakhtin were among those who explored the novel and its peculiarities exceptionally thoroughly. Comparing the epic and the novel became the starting point for their thinking. Lukács $(1971)$ pronounced late $19^{\text {th }}-$ early $20^{\text {th }}$ century the era of the novel, with romantic irony (or "irony as mysticism," which is "the highest freedom that can be achieved in a world without God" (Lukács, 1971, p. 93)) being its chief artistic principle. Bakhtin (1975) identified the key characteristics of the novel as a dynamic genre meant to portray dynamic and incomplete reality:

It is plasticity itself. It is a genre that is ever questing, ever examining itself and subjecting its established forms to review. Such, indeed, is the only possibility open to a genre that structures itself in a zone of direct contact with developing reality (Bakhtin, 1975, p. 330$331)$.

\section{Methods.}

Modern literary criticism is at the stage of active methodological transformation because the tangible metamodernist experience and understanding of reality directly affect the formation of paradigmatic principles in the study and rethinking of analytical concepts of scientific discourse. One such approach, which shows maximum flexibility in the horizon of modern humanities, is 
narratology, especially in its postclassical status. To re-read the novel of the late nineteenth - early twentieth centuries, we applied the eloquent metaphor of Gérard Genette. In the current metamodernist development of reality, a special place belongs to one of the most appropriate concepts proposed by the French scientist. Genette (1998) introduced the motif of "dizziness" into the space of literary studies (as separate concepts, i.e., "dizzying principle of symmetry" (Genette, 1998, p. 62) or "dangerous space-dizziness" in the discourse of modern culture (Genette, 1998, p. 126), and analytical approaches in the study of the works of individual authors, such as the essay on Alain Robbe-Grillet Fixation of Dizziness (as cited in Genette, 1998) or in work on Jorge Luis Borges. The latter, according to the researcher, sought to "restrain his dizziness or doubt in the secret labyrinths of erudition" (Genette, 1998, p. 144). Coming out of the bosom of French structuralists and building a literary paradigm of narratology, Genette tried, on the one hand, to help a modern man to overcome the growing anxiety, and proposed a perfect "geometry of literature," and on the other hand, he understood the nature of "creative experience" in more and more detail, which is the core of "dizziness." For a relatively short period (in the coordinates of the humanities): from 1969, when in Grammaire $d u$ "Decameron" by Tzvetan Todorov the concept of narratology was substantiated - to 1997, when David Herman's Scripts, Sequences, and Stories: Elements of a Postclassical Narratology offered a new meaning of the concept, narratology echoed a truly dizzying path of assertion, self-reflection, and now - tectonic selftransformation as a literary methodology. Having absorbed the potential and possibilities of structuralism, providing narration with a rational and conceptual justification, the "narrative theory" has multiplied by at least five times, as differentiated by Papusha (2013): 1) transdisciplinary narratology, which goes beyond literary studies, 2) transtextual narratology that goes beyond the text into context 3) transmedial narratology that goes beyond the verbal text, 4) transgenetic narratology that goes beyond the epic genre, 5) transfictional narratology that goes beyond fiction (Papusha, 2013).

For the narratological set of tools to acquire its applied significance given the current demands of modern understanding of literary and artistic phenomena, it is necessary to introduce it into a broader context. In parallel with the narratological discourse, another research direction developed in psychology, namely, cognitive psychology, thoroughly represented in the studies by George Miller, Jerome Bruner, Ulrich Neisser, and Ed Smith. In the preface to Cognitive Psychology, Robert Solso noted that in working on his book for a long time, he enjoyed reading and re-reading. Thus, in the chronotope of ontological research, narratology as a theory of narrative and cognitivism as a science of the nature of human thought metaphorically met, performing their tasks, which are, according to R. Solso, "both ambitious and exciting" (Solso, 2006, p. 34). At the intersection of these two methodologies in domestic literary criticism, a wholly logical and "dizzying" question is formulated about the subject of study of cognitive narratology: "what is the subject of study of cognitive narratology: textual structures or structures of human thinking?" (Sobchuk, 2012, p. 112).

At the same time, the paradigm becomes even more complex, rather than "dizzying and exciting," as its methodological understanding occurs synchronously with the active transformation of the existential narrative. The assertion of the narratological approach to literary and artistic phenomena took place in the coordinates of postmodernism, when chaos sought to 
order and a certain systematization. Postclassical narratology is differentiated and becomes relevant simultaneously with the understanding of metamodernist concepts and principles. And if the scientific approach seeks to be legitimized, it must assume the mood of the era, enter the ontological space as not so much the search for meaning as the search for forms of balance between work and text, meaning and sense, perception and understanding, analysis and interpretation. Attempts to "inscribe" narratological tools first in the prism of cognitivism and then introducing this construction into the space of metamodernism seem to be an even more exciting and even more ambitious task. Tawfiq Yousef is quite right in characterizing metamodernism as the dominant cultural logic of modern times (Yousef, 2017). According to the researcher, who compares modernism, postmodernism, and metamodernism, the latter "tries to surpass modernism and postmodernism to correspond to modern cultural regimes. Its basic tenet is that faith, trust, dialogue and sincerity can help overcome the postmodern irony and alienation" (Yousef, 2017, p. 33). Thus, the study of literary texts regardless of their belonging to the era of creation (premodernism and modernism) in the system of methodological approaches to metamodernism, seems promising in the process of marking the newest humanitarian horizon.

To develop a systematic approach to the subject of study, one should consider the dynamic process of self-identification in each area of scientific knowledge as mentioned above. The search for an answer to the relevant question of Oleg Sobchuk on the subject of cognitive narratology can be introduced into the space of geometry (imitating Genette) and primarily explore the planimetric environment - to streamline the understanding of the nature and functioning of "textual structures," and then with the help of cognitive tools to model a stereometric space in which "structures of human thinking" will dominate the text and create a metafictional reality. It is necessary to agree with the opinion of Prof. Tatiana Chernihivska that the central postulate of today is the brain, primarily - its secrets and possibilities. Thought concepts are increasingly active and complex with individual elements of the artistic world. Depending on the rotation of the traditional but productive, "polaroid lens," the focus of research may be centered around a certain element of the cognitive chain (perception, images recognition, attention, memory, imagination, language functions, developmental psychology, thinking, problem-solving, human intellect, artificial intelligence). In each particular context, the modeling of an artistic narrative uniquely takes place, emphasizing either textual signposts or receptive keys and assumptions. In the first chapter of Cognitive Psychology, Solso (2006) quotes Haugard Gardner:

Through the development of new logical tools, the widespread introduction of computers, the application of scientific methods in the study of human psychology and cultural customs, discovery in the field of structure and function of the nervous system, we have achieved a deeper understanding of the issues originally formulated by Plato, Descartes, Kant, and Darwin" (Solso, 2006, p. 34).

There is no doubt that the increase of knowledge in a particular field of research expands and deepens the possibilities for further study. Still, there are those aspects of the functioning of human consciousness that are extremely difficult to be exposed to a comprehensive analysis, clear systematization, and differentiation. One of the areas where personal reception creates an individual projection of the canonical text is fiction. In particular, one of the productive genres - 
the novel - needs a new understanding within the definite content of the triad "narratology cognitivism - metamodernism," which is the subject of the proposed study.

\section{Results.}

Let us consider the specifics of the novel as a genre based on the works of two authors - each of them demonstrated the original talent, explored unique issues, embodied the canon of the novel genre given the national culture and understanding of the historical era, synchronous belonging to which gives grounds for studying aspects of their work in one methodological context. These are Lucy Maud Montgomery (Canada) and Eleanor Porter (USA).

Lucy Maud Montgomery's (1874-1942) work played an essential role in developing the Canadian novel. Although her books generally evoke interest as vibrant examples of "children's literature," we would like to argue that the range of topics discussed in L.M. Montgomery's works (a woman's place in social hierarchy, young teachers' professional development, and difficulties of their trade, dealing with death and sickness, fear of loneliness and alienation from society) far exceeds the boundaries of literature "for children" and "about children."

From the viewpoint of modeling a Metamodernist chronotope, we should note the nondiegetic explicit narrator being dominant in the novels of the Anne of Green Gables series as a specific feature of said novels' narrative structure. Although the sphere of their existence is limited to the exegesis (meaning that the narrator does not participate in any narrated events), the narrator's position is revealed through a combination of lyrical interjections; comments; assessments of the environment, actions, and characters. In nature descriptions, for example, the point of view of the narrator is transformed into a personal point of view. The narration takes place through the representation of the protagonist, accurately conveying the expressiveness, syntactic, lexical, and stylistic peculiarities of her language:

It was October again when Anne was ready to go back to school - a glorious October, all red and gold, with mellow mornings when the valleys were filled with delicate mists as if the spirit of autumn had poured them in for the sun to drain - amethyst, pearl, silver, rose, and smoke-blue. The dews were so heavy that the fields glistened like cloth of silver, and there were such heaps of rustling leaves in the hollows of many-stemmed woods to run crisply through. The Birch Path was a canopy of yellow, and the ferns were sear and brown all along it (Montgomery, 2016, p. 175).

Along with hypertrophied sincerity and highly intensive emotional saturation, the text allows space for the perceptive level of viewpoint, with the narrator unveiling their own evaluations of characters and events. To this end, we should consider the significance of irony, which facilitates the unraveling of the fictional world in accentuating the contrast between the heroine's poetic worldview and the narrator's viewpoint which leans toward a more realistic stance:

...but by the time it reached Lynde's Hollow it was a quiet, well-conducted little stream, for not even a brook could run past Mrs. Rachel Lynde's door without due regard for decency and decorum; it probably was conscious that Mrs. Rachel was sitting at her 
window, keeping a sharp eye on everything that passed, from brooks and children up (Montgomery, 2016, p. 1).

Basing her writing off of the Bildungsroman tradition, L.M. Montgomery updated this genre quite substantially, enriching it with new themes and problems (the influence of literature and culture on personality development, the role of friendship in a young person's life, creative reimagining and transformation of one's reality as a way to overcome inner conflict, etc.). At the same time, we should note that her version of the Bildungsroman is frequently combined with the regional novel, a characteristic genre of Canadian literature meant to portray essential characteristics of Canadian nature and locations where the author spent a significant portion of their life. The conceptual environment where the characters live and act - the little village of Avonlea - is a composite image based on the author's impressions of different locations on Prince Edward Island, where L.M. Montgomery lived throughout her childhood and youth. By fiercely protecting her native town from all outsider criticism, Anne expresses her wish to change Avonlea for the better, which is revealed in very concrete actions undertaken by the protagonist and her friends (e.g., starting a Village Improvement Society). To this end, it makes sense to talk about "new sincerity" to which Metamodernist perception of the world aspires.

The main issues that determined the form, content and structure of L.M. Montgomery's fiction (devotion to one's home, creative freedom, girls' (or women's) search for their place in society) are further developed in the Pat of Silver Bush dilogy (1933-1935) and the Emily trilogy (1923-1927).

Pat Gardiner is similar to Anne Shirley in that she is also bestowed with a particular "fairy gift," which denotes her ability to perceive the world around her in a creative way, transforming it through the means of her imagination. Similarly to the Anne of Green Gables series, personification (especially when it comes to different house images) is one of the key, illuminating tropes in the imaginary world of the novel, which not only helps to characterize specific aspects of the fictional space but also supports the image of the heroine as a creative person: "Oh, I've got such a lovely home," breathed Pat, clasping her hands. "It's such a nice friendly house. Nobody ... nobody ... has such a lovely home. I'd just like to hug it" (Montgomery, 1989, p. 159). Pet keeps in touch with her native Silver Bush and other houses, talking to them, guessing their surreptitious dreams and aspirations:

Pat called it the Long Lonely House. <...> "It wants to be lived in, Judy," she would say wistfully"; "Pat always felt as if the house was chuckling to itself over some joke nobody but itself knew, and she liked the mystery. She wouldn't have liked Silver Bush to be like that: Silver Bush mustn't have secrets from her (Montgomery, 1989, p. 24).

However, it should be noted: while the Anne novels are dominated by a narrative point of view, the Pat novels are dominated by a personal point of view. The events are narrated and explained from the viewpoint of the seven-year-old Pat Gardiner ("Mother was lying on her pillows, white and spent after that dreadful headache" (Montgomery, 1989, p. 29)); following G. Genette's typology, we might call this "internal focalization" (with the narrator only telling us what the 
character knows); in W. Schmid's typology, this would be a "personal" point of view. Therefore, we may conclude that these works of fiction exemplify a "double narrativity" strategy utilized to achieve a more convincing depiction of events and their perception.

Emily Starr, in turn, dreams of growing up and becoming a "famous authoress" ("I haven't any intention of dying. I'm going to live - for ages - and be a famous authoress - you'll just see if I don't, Aunt Elizabeth Murray!" (Montgomery, 1923, p. 39)). After her father's death, she is prone to feeling incredibly lonely. However, she can find solace in dreaming and writing. In certain moments, Emily can see the world around her as a "flash":

It had come with a high, wild note of wind in the night, with a shadow wave over a ripe field, with a greybird lighting on her window-sill in a storm, with the singing of "Holy, holy, holy" in church, with a glimpse of the kitchen fire when she had come home on a dark autumn night, with the spirit-like blue of ice palms on a twilit pane, with a felicitous new word when she was writing down a "description" of something. And always when the flash came to her, Emily felt that life was a wonderful, mysterious thing of persistent beauty (Montgomery, 1923, p. 7-8).

Essential factors in the rendering of the fictional world include personification ("The Wind Woman was always around; and there were the trees - Adam-and-Eve, and the Rooster Pine, and all the friendly lady-birches" (Montgomery, 1923, p. 1)) and antonomasia ("Father had had so many of them for her - "sweetheart" and "darling" and "Emily-child" and "dear wee kidlet" and "honey" and "elfkin." He had a pet name for every mood, and she had loved them all" (Montgomery, 1923, p. 35)).

The narrative configuration of L.M. Montgomery's novels is part of a broader literary context, with the late 19th - early 20th-century Canadian novel represented by genres such as the historical novel, Prairie novel, regional novel, Bildungsroman, etc. When analyzing L.M. Montgomery's works, we should emphasize her contribution in updating Bildungsroman by combining it with regional story and enriching it with new themes and problems (women's position in society; young teachers' professional development; the role of literature, culture, creative pursuits in young people's lives, etc.). Poetic peculiarities of this Canadian writer's novels give us grounds to study the poetics of her fiction within the paradigm of cognitive narratology due to profound psychological analysis, but also due to a broad range of authorial narrative solutions unraveling the psychological chain: firstly, in terms of intention presentation, later on - to recognize textual markers to understand the nature of the creative idea and its implementation.

To try a comparative typological study within the historical era, the dominant mood of the experience of its age, embodied in the original narrative decisions in the literary and artistic work, we will examine the literary works by another author - Eleanor Porter (USA). First of all, it is necessary to note that an essential aspect of the existence of the artistic world, its comprehension and research is (re)reading the literary work as a process of decoding meanings, (re)understanding of reality in the mirror of Literature, interpretation of existential phenomena through the prism of mental plexuses at the textual and metatextual levels - the literary criticism studies offer the 
scientific discourse an inexhaustible set of embodiments of semantic and cognitive paradigms, as well as the coordinates in the plane of a work of art. In our opinion, literary works about a child and the world of childhood constitute an interesting and promising niche for scientific research, namely - the literary embodiment of the ontological category "childhood" and the further development of the receptive model of this phenomenon. The novel by the American writer Eleanor Porter Pollyanna (1913) is the material for the study of the receptive potential of childhood in the context of the narratological approach from the evaluative standpoint of metamodernist experience of the world. It should be noted that the choice of the novel is because the philosophical and historical understanding of the phenomenon of childhood in the transition period (late nineteenth - early twentieth century) has reached a kind of categorical "crystallization." All periods of formation and development of philosophical thought more or less fragmentedly correlated with childhood: from Plato, Aristotle, and Democritus to the classical German philosophers (I. Kant, G. Hegel, A. Disterweg) - childhood "nurtured" in philosophical thinking as an intermediate link in the process of forming a social individual. And only in the middle of the 19th century, the vector of the child's gaze shifted in the direction of its "personalized" vision. For example, L. Feuerbach pondered the still unresolved question:

What is a child for? Is their destiny to be on the other side of childhood? No, because why would they be children then? Nature completes its work with every step it takes, <... A child does not exist to become an adult - how many people die as children! - a child exists for its own sake, so it is satisfied and finds pleasure in itself (as cited in Kochubey, 2014, p. 260-261).

To understand the narrative nature of the literary text, which focuses on childhood as an idea, it is necessary to take into account the basic concepts of childhood, in particular, the theory of the historical origin of childhood. Vygotsky (2004) argues that the development of the child's personality is not determined by the laws of natural/physiological formation of the organism (Vygotsky, 2004). According to Elkonin (2005), childhood correlates not with physical imperfection, but with the social manifestation of the individual (Elkonin, 2005). It is aslo essential to consider the cultural and anthropological concept of childhood. Mead (2004) considers the role of socio-cultural factors in the formation of children's personality, namely - the mechanism of influence of objective and subjective aspects of human society on the "formatting" of the universal biological code in a unique child's character) (Mead, 2004). Social concepts are important as well (interpreting childhood as a particularly valuable - and always unique - reality of "unfolding" of the human personality (Cohn, 2004; Mitrofanova, 2017; Davis, 1996; Garbarino, 1987). In addition, we consider the approach suggested by Slavova (2002) to be an integral segment of scientific studies, since it introduces specific poetic qualities of literature about a child into a holistic paradigmatic context of both childhood and literature (Slavova, 2002).

As evidenced by the analytical studies of domestic and foreign scholars, the issue of childhood in its philosophical, social, cultural, aesthetic contours, etc., is an essential area for reflection and scientific discussion. We consider, first of all, the urgent need for "confrontation" with hitherto new generations of readers to be a probable impetus for attempts to comprehend the essence of childhood paradigmatically. Exploring the specifics of formatting narrative strategies, 
it is necessary to take into account the receptive space, which will "enter" the fictional world and in which it will acquire the needed markers because the request comes from the reader of the metamodern world. Taking into account the reasoning and conclusions of researchers of generational phenomena, we assume that the generation of "google-babies" or "alpha" testifies to a kind of turn of the child to "pure" childhood, not dissolved in archetypal matrices or today's indispensable digital space. Metamodernist "New Sincerity" (G. Denber) will need an appropriate artistic solution. Thus, the semantic manifestation of childhood in the poetic system of the work of art and the following parameters of its reception becomes especially relevant in modern literary criticism.

E. Porter's novel Pollyanna, written in 1913 (at the culmination of the history of existentialism), offers existential phenomena and, in part, dichotomies for comprehension and analysis. The work's plot revolves around the figure of 11-year-old orphan Pollyanna Whittier, who moves from an orphanage of the Ladies' Aid to Aunt Polly - her only relative in the small town of Beldingsville. The novel's plot actualizes numerous variants of manifestation of the category of "childhood" at the poetic level of modeling the artistic world. The narrative strategy of the story represents the artistic embodiment and logical structuring of key poetic markers of childhood, which can be best systematized using the concept of "frame." Proposed by M. Minsky in 1974, for the area of artificial intelligence research, this concept refers to the cognitive structure in the phenomenological field of a man, based on "possible knowledge of typical situations and related expectations of the properties and relations of actual or hypothetical objects" (Minsky, 1979, 288). Thus, the frame system is a kind of hierarchical ordering, in which a specific "top" is subject to "slots," "macro positions" and "terminals." Given that Genette's "geometry" is based on the idea of harmony and order, which is embodied in a particular modeled artistic world of the literary work, we have reason to say that the narrative strategy of E. Porter's novel is a well-ordered cognitive structure, whose "direct functioning" is associated with the receptive process. Thus, to analyze the artistic components of the matrix of "childhood" in E. Porter's novel, it is entirely appropriate to use a semantic frame model.

The starting point of modeling the frame structure of childhood in the artistic space of the novel is the tendentious authorial conceptualization of this category: the child protagonist is not opposed to other characters, not removed from the system of images to a particular semantic position. Here we can emphasize the intentional strategy of "encoding" meanings: out of the mouth of the child and in their actions, one can touch the most painful and intimate, one can attract attention, evoke empathy, make the desired impact. Therefore, we consider "childhood as an author's strategy" the "top" of the frame. To express cognitive processes, childhood acquires a special meaning, designing the reception toward enhanced empathic identification.

The "terminals" of this frame structure are concretized under the semantic specificity of the novel, so the interpretation is greatly multiplied: each new reading and comprehension gives rise to new meanings of the category "childhood." The study of frame components in the narrative strategy of E. Porter's novel is based on the axiomatic statement that the "frame" structuring of a specific paradigm is characterized by its inconsistency and is directly related to the interpretive and methodological model, as well as analytical guidelines. The artistic world of childhood in the 
novel by the US writer offers a significant palette of structural elements of the frame "childhood" in the story. The reader's first acquaintance with the heroine takes place at the moment of her deep loneliness: first, her mother died, and soon her father, and the charity organization sent the child to her only relative, her mother's sister, who was forced to take care of the niece. The opposition "childhood" - "loneliness" seems obvious, but the development of the artistic paradigm of childhood involves correlations, which seem impossible at first glance. Pollyanna's loneliness, clearly outlined in the first pages of the novel, as an objective quality of her childhood, triggers the mechanism of meaning-creation, forms the "non-childish" reality around the child, generating hitherto incomprehensible meanings and questions.

The existential significance of the category of childhood, proposed by E. Porter, is expressed by a redirected point of view: the voice of the narrator sounds like the voice of a character. After all, the critical idea is embedded in the mouth of Mr. Pendleton, once in love with Pollyanna's mother:

Pollyanna, many years ago I fell in love with a woman. I was hoping one day to bring her to this house. $\langle\ldots\rangle$ But $\langle\ldots\rangle$ I couldn't bring her here $<\ldots>$ Since then, this house has become a pile of gray stones for me, not a home. It needs a woman's hand and heart - or a child's presence <...> to become a home (Porter, 2004, p. 141).

Thus, the "child's presence" is a marker of "vitality" necessary for further "being." And identical with the female in its importance, the child's soul is an attribute of a new beginning, purity, possible "tomorrow." Thus, in the narrative structure, thanks to the frame, the basic levels of the point of view are transformed - the perceptual level is specified. Metamodernist world cognition is fully embodied here as not the oscillation of good-bad or positive-negative, but in the perception of everything simultaneously suitable at a particular moment of being.

The correlation "childhood" - "self-awareness" is vital for understanding the narrative specificity of the analyzed frame: childhood as a category acquires an incredibly holistic embodiment given its reflection and self-reflection. Awareness of its uniqueness at its unfolding the semantic load of the model implemented by the author brings the category of "childhood" in a qualitatively different plane, where each of the possible receptions is implemented in existential contours. The teenage girl, who is experiencing loss after loss, once again is forced to come to terms with the evil turns of fate (here it is necessary to emphasize the differentiation of narrative and receptive assessments: the reader considers them evil, but the girl does not), clearly defines its purpose: it will make the world (= reality) ) brighter (= happier). At the same time, she is overwhelmed with fear because she will not be hugged, she will not be regretted because she is entirely alone. The correlation "childhood" - "self-awareness" appears as a kind of autonomous semantic structure in the narrative because it has no motivating context. Growing up "like this," Pollyanna radically changes the fate of not only John Pendleton ("Girl," he said, "I want you to come to me as often as possible. Promise? I'm completely alone, and I need you" (Porter, 2004, p. 130), but also unexpectedly for the whole town heals the seriously ill Mrs. Snow ("It's worth seeing you once, and it's impossible to forget. It's a pity you weren't there yesterday. I needed you yesterday" (Porter, 2004, p. 72). The hyperemic presentation is also achieved through certain plot 
elements, such as the rescue of Jimmy Bean (a homeless orphan boy to whom Pollyanna gave not only a home but also a family), a new chance for happiness for, formidable at first glance, but, in fact, deeply unhappy, Aunt Polly and Dr. Chilton, thirsty for love - "non-childish" incarnations of childhood, embodied in the figure of Pollyanna, lead to (new)(re)realization of this category.

Joy as an ontological phenomenon determines the leitmotif of the novel, and its narrative representations specify the frame structure of the narration. This gives grounds to consider Pollyanna by Eleanor Porter as a literary source for the development of the concept of "joy" in the artistic world of a literary work. The ability/willingness to rejoice, the ability to "play for joy" the paradigmatic significance of joy as a way of worldview concretizes the artistic model of "childhood." An unusual manifestation of joy, a fundamental denial of joy as a pleasant emotion or a sublime mental state, testify to the poetic and, consequently, a receptive feature of this phenomenon. More than a century of long-standing tradition finds its new reading in the coordinates of metamodernism, which testifies to the need for a neo-metallic perception of the world. "Game of Joy," examined in the frame structuring of the novel, offers a philosophical concept of "living" the reality: "The essence of the game is to find something to rejoice in, it does not matter what" (Porter, 2004, p. 36). For example, a completely unexpected narrative decision: to rejoice when crutches were presented instead of a doll:

Well, goodness me! I can't see anythin' to be glad about - gettin' a pair of crutches when you wanted a doll! < ..> Goosey! Why, just be glad because you don't need - 'em!" exulted Pollyanna, triumphantly. "You see it's just as easy - when you know how! (Porter, 2004, p. 37).

This passage testifies to the convincing semantic "privilege" of a literary work about a child because it gives habitual reasoning the status of truth. Moreover, it should be noted that we are talking about existential concepts. The conceptual significance of the game in the history of culture is argued in the studies of the Dutch philosopher Johan Huizinga. Like every game, the "game of joy" has its rules. The social significance of the game is, first of all, in understanding the possible losses and benefits, as well as in following the directions to succeed. The game proposed by E. Porter is built on the same principles: the culmination of Pollyanna's game is her life: when an 11year-old "slender little girl in the red-checked gingham with two fat braids of flaxen hair hanging down her back" (Porter, 2004, p. 17) will teach a gloomy town to live in joy and enjoy life, she will face a difficult question - why should she rejoice herself, lying bound to bed? Thus, in the gradual concretization of the artistic narrative, the frame acquires not only significant semantic correlations, not only carries out a clear intention but also maximizes the receptive horizon of the work, transforming the meanings of the narrative into markers of interpretation.

The metamodernist reception of the novel's artistic world is facilitated by a masterful, deeply psychologized childhood narrative. Thanks to the author's strategy, the effect of complete identity (in the words of metamodernism, "true authenticity" or "real reality") of the world, which is the subject of reflection, and the world, which is a fragment of artistic integrity, is achieved. The importance of the moment, the value of what is "here-and-now" are concentrated in a detailed reproduced vortex of real life, which is not a preparation for tomorrow but is valuable today 
because it is life itself. We can notice the modernist chronotope of the envisaged metamodernist question - the search for harmony of the world and in the world. The narrative of E. Porter's novel comes to an end together with the answer to Pollyanna's central question - HER "joyful" "adult" town of Beldingsville is why she will rejoice, and the "non-childish" game, the rules of which are perfectly mastered by all the adults around, will put her back on her feet. Markers of childhood in the artistic space of a literary work, the idea of which grows in the canon of anxieties of modernism, convincingly fit into the axiological paradigm of the mood of the modern "cultural era." The frame structuring of the narrative makes it possible to identify specific patterns of the poetic model in the semantic plane of the work of art through oppositions and synthesis of conceptually dichotomous concepts.

\section{Conclusions:}

The development of the narratological paradigm of the latest literary studies significantly expands the possibilities of reading a work of art. At the same time, the active synthesis with cognitivism opens new horizons for analytical studies. Novel's history as a genre makes it possible to identify the main stages of formation of methodological foundations for understanding the nature, essence, artistic canon, to outline the most characteristic features that find their original embodiment in each idiosyncratic system. The narrative strategies of Lucy Maud Montgomery and Eleanor Porter primarily reveal the author's intention and build the art world in the perspective of in-depth psychological analysis, appealing to the imagination, thinking, memory, modeling images in the mind of the reader. Particular attention should be paid to the stylistic means by which the author's idea enters the reader's living space. Historically belonging to the era of the premonition of modernism and the unfolding of the modernist worldview, both authors prognostically enter the area of the metamodernist search. One way or another, their works seek to find harmony of the individual with the world, their heroes (in particular, heroines) represent the "new sincerity" and "meta-cuteness" that best fit into the latest context of humanities knowledge.

"Dizziness" is a way of thinking that brought Gerard Genette out of structuralism and led to the development of the classical model of narratology, although the researcher sought to master the complexity of artistic space-time, so he proposed a holistic system of text signposts. At the present stage, when postclassical status moves narratology toward the convergence with the study of the nature of human thought, Genette's metaphor is only further expressed and acquires new modifications. After all, homo- and hetero-narration give fundamentally different reflections in projections, for example, on perception, on images recognition, on marking of memory horizons, and so on. Simultaneously with the expansion of visualization, the levels of imagination or thinking become even more hypothetical, in part rather amorphous, as philosophers and culturologists insist, proposing concepts for understanding metamodernism as a "new cultural age" (Yousef, 2017).

Thus, for a holistic study of the novel genre in the synthesis of modern literary approaches, one should correlate narrative models with aspects of cognitive psychology, which allows for deepening poetic research at all stages of the artistic world - from the author's idea to the latest interpretations. One of the options for answering the fundamental question of Oleh Sobchuk might 
AWEJ for Translation \& Literary Studies Volume, 6 Number 1. February 2022

Narrative Aspects of the Novels by Lucy Maud Montgomery

Matsevko-Bekerska, Nikolenko, Kokhan,\& Nikolenko

be not "what?," but "how?" - how exactly does the mutual transformation of "textual" and "mental" structures occur in each stylistic system?

About the Authors:

Lidiia Matsevko-Bekerska, Doctor of Sciences (Dr. Hab.), Professor, is the Head of the Department of World Literature, Ivan Franko National University of Lviv, Ukraine.

ORCID: https://orcid.org/0000-0003-4626-5904

Olha Nikolenko, Doctor of Sciences (Dr. Hab.), Professor, is the Head of the Department of World Literature, Faculty of Philology and Journalism, Poltava V.G. Korolenko National Pedagogical University, Ukraine. ORCID: https://orcid.org/0000-0001-7374-7226

Roksoliana Kokhan, Ph.D., is an Associate Professor at the Department of Foreign Languages for Natural Sciences, Ivan Franko National University of Lviv.

ORCID: https://orcid.org/0000-0001-8639-9486

Kateryna Nikolenko is a Ph.D. student of the Department of World Literature, Faculty of Foreign Languages, Ivan Franko National University of Lviv, Ukraine.

ORCID: https://orcid.org/0000-0002-1299-8483

\section{References}

Bakhtin, M. (1975). Issues of Literature and Aesthetics. Moscow: Fiction.

Davis, K. (1996). The Child and the Social Structure. Journal of Educational Sociology, 14(4), 217-229.

Elkonin, D.B. (2005). Child Psychology: Textbook for Universities. Moscow: Academia.

Esalnek, A.Ya. (1991). Theoretical Foundations of the Typological study of the Novel. Typology of the Novel, 4-36.

Garbarino, J. (1987). The Significance of Ethnic and Cultural Differences in Child Maltreatment. Journal of Marriage and the Family, 45(4), 773-783.

Genette, G. (1998). Figures: In 2 volumes. Volume 1-2. Moscow: Sabashnikov Publishing House. Hegel, G.W.F. (1971). Aesthetics: In 4 volumes. Moscow.

Kochubey, T. (2014). Philosophy of Childhood in the Legacy of Teachers-Thinkers of the XVIIXX Centuries. Problems of Modern Teacher Training, 10(3), 260-261.

Cohn, I.S. (2004). Childhood as a Social Phenomenon. Journal of Social Policy Research, 2(2), 151-174.

Lukács, G. (1965). Die Theorie des Romans. Darmstadt.

Mead, M. (2004). Culture and the World of Childhood: Selected Works. Moscow: Nauka.

Minsky, M. (1979). Frames for the Presentation of Knowledge. Moscow: Energy.

Mitrofanova, S.Yu. (2017). Conceptualization of the main approaches to the study of childhood in sociology. Sotsiologicheskie issledovaniya, 3, 3-15.

Montgomery, L.M. (2008). Anne of Green Gables. London: Penguin Random House.

Montgomery, L.M. (2021a). Emily of New Moon: (Complete Annotated). Independently published. Montgomery, L.M. (2021b). Pat of Silver Bush. London: Sourcebooks Fire.

Arab World English Journal for Translation \& Literary Studies 
AWEJ for Translation \& Literary Studies Volume, 6 Number 1. February 2022

Papusha, I. (2013). Modus Ponens. Essays on Narratology. Ternopil: Krok.

Porter, E. (2004). Pollyanna / trans. from English by B. Gora. Kyiv: Shkola.

Slavova, M. (2002). Cinderella of literature. Theoretical aspects of children's literature. Kyiv.

Sobchuk, O. (2012). Rethinking the Concepts of Narrative, Character and Focalization in Modern Conative Narratology. Magisterium, 48, 108-113.

Solso, R. (2006). Cognitive Psychology.6th ed. St. Petersburg: Piter.

Vygotsky, L.S. (2004). Psychology of human development. Moscow.

Yousef, T.(2017). Modernism, Postmodernism, and Metamodernism: A Critique. International Journal of Language and Literature, 5(1), 33-43. 